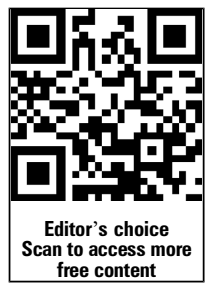

${ }^{1}$ Department of Ophthalmology, Wills Eye Hospital, Philadelphia, Pennsylvania, USA

${ }^{2}$ Department of Engineering, University of Utah, Salt Lake City, Utah, USA

\section{Correspondence to} Dr Larry A Donoso, Department of Ophthalmology, Wills Eye Hospital, PO Box 53429, Philadelphia, PA 19105, USA;

Idonoso@vision-research.org

Received 8 October 2013 Accepted 3 November 2013 Published Online First 28 November 2013
CrossMark

To cite: Schubert $C$, van Langeveld MC, Donoso LA. $\mathrm{Br} J$ Ophthalmol 2014;98:159-161.

\title{
Innovations in 3D printing: a 3D overview from optics to organs
}

\author{
Carl Schubert, ${ }^{1}$ Mark C van Langeveld, ${ }^{2}$ Larry A Donoso $^{1}$
}

\section{ABSTRACT}

$3 D$ printing is a method of manufacturing in which materials, such as plastic or metal, are deposited onto one another in layers to produce a three dimensional object, such as a pair of eye glasses or other 3D objects. This process contrasts with traditional ink-based printers which produce a two dimensional object (ink on paper). To date, 3D printing has primarily been used in engineering to create engineering prototypes. However, recent advances in printing materials have now enabled $3 \mathrm{D}$ printers to make objects that are comparable with traditionally manufactured items. In contrast with conventional printers, 3D printing has the potential to enable mass customisation of goods on a large scale and has relevance in medicine including ophthalmology. 3D printing has already been proved viable in several medical applications including the manufacture of eyeglasses, custom prosthetic devices and dental implants. In this review, we discuss the potential for 3D printing to revolutionise manufacturing in the same way as the printing press revolutionised conventional printing. The applications and limitations of 3D printing are discussed; the production process is demonstrated by producing a set of eyeglass frames from 3D blueprints.

\section{INTRODUCTION}

In 1620, the English Philosopher Francis Bacon articulated that the printing press, firearms and the nautical compass changed the state of the world forever and ushered in the modern world. Ironically, today it is possible to $3 \mathrm{D}$ print firearms, a compass and $3 \mathrm{D}$ printers. The Gutenberg printing press could produce an astonishing 3500 printed pages per day. This actually became the first assembly line leading to mass production. By the year 1500 over 20 million books were printed. ${ }^{1}$ Other printing techniques followed including such methods as lithography (a stone or plate used to print a whole page), dot matrix, laser or inkjet printers (transfers ink to paper), and digital printing (transfers a digital image to a printing surface). A common feature of all of these methods is that the final image is a two dimensional image.

In the early 1980s Charles Hull invented 3D printing ${ }^{2}$ which he described as stereolithography (STL) or the 'printing' of successive layers of material on top of each other to create a 3D object. The STL may specify information about the object to be printed such as its colour, texture, layer thickness, etc. A large number of such files are available commercially. To demonstrate this new technology, STL files were used to 'print' a pair of conventional eyeglass frames (figure 1), an unconventional multicoloured statute consisting of a variety of shapes, angles, curves and intricate details in one layer

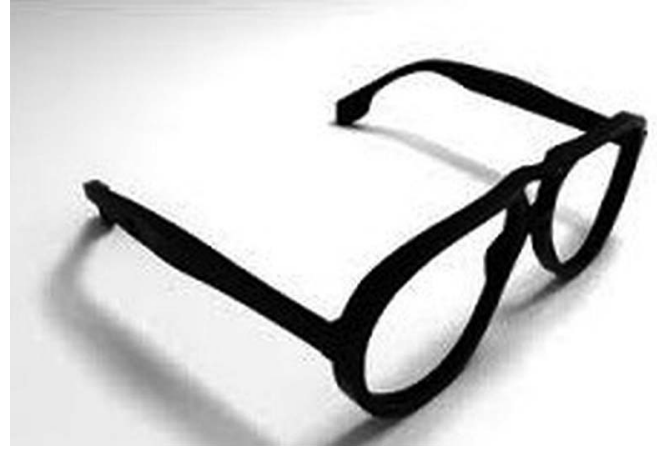

Figure $13 \mathrm{D}$ printed eye glass frames.

(figure 2), a multilayered object consisting of three separate spheres (figure 3), a 3D printer printed by a $3 \mathrm{D}$ printer (figure 4 ) and a video demonstrating $3 \mathrm{D}$ printing (figure 5 ).

Another feature of 3D printing involves economies of scale. While traditional manufacturing methods are still cheaper for large scale production, the cost of $3 \mathrm{D}$ printing is becoming competitive for smaller production runs. NASA just produced a fuel injector for one of their rockets at a third of the cost and two-thirds of the time compared with traditional methods and plans to have a $3 \mathrm{D}$ printer on board in their next space flight. ${ }^{3}$ Furthermore,

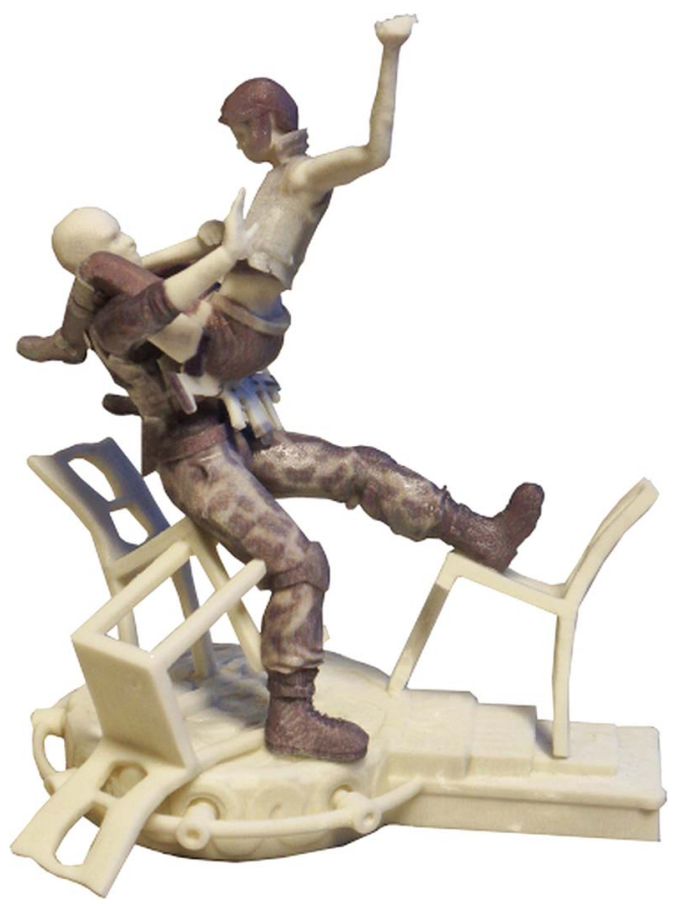

Figure 2 Complex multicolored 3D printed sculpture. 


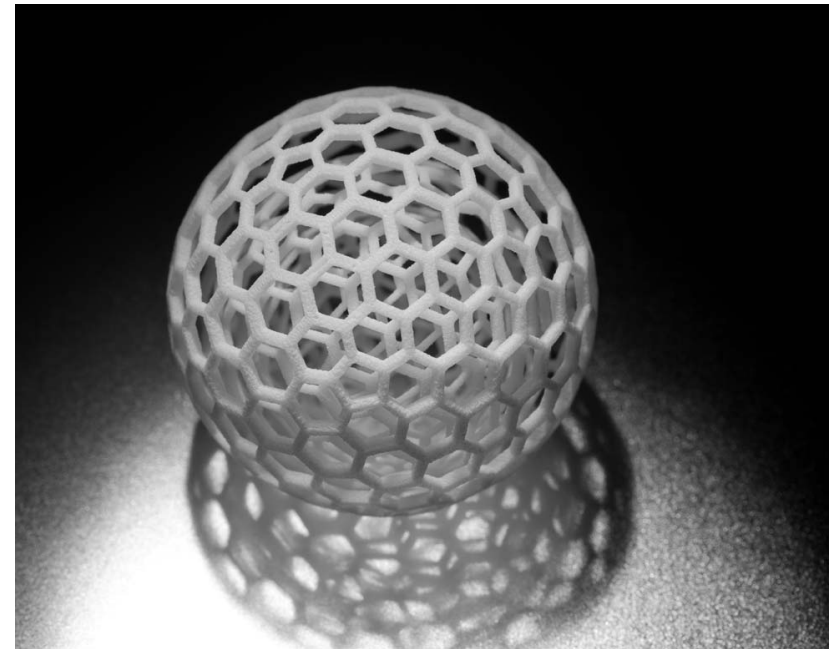

Figure 3 Multiple series of spheres 3D printed inside each other.

in $3 \mathrm{D}$ printing, the cost of the set-up is minimal which allows for a high degree of customisation, as the cost of the first item is the same as the last. Hence, 3D printing is ideal for making one of a kind items at cost-effective prices. For example, it may be possible using this technique to rapidly screen new potential therapeutic drugs on $3 \mathrm{D}$ printed patient tissue, greatly cutting production costs and time.

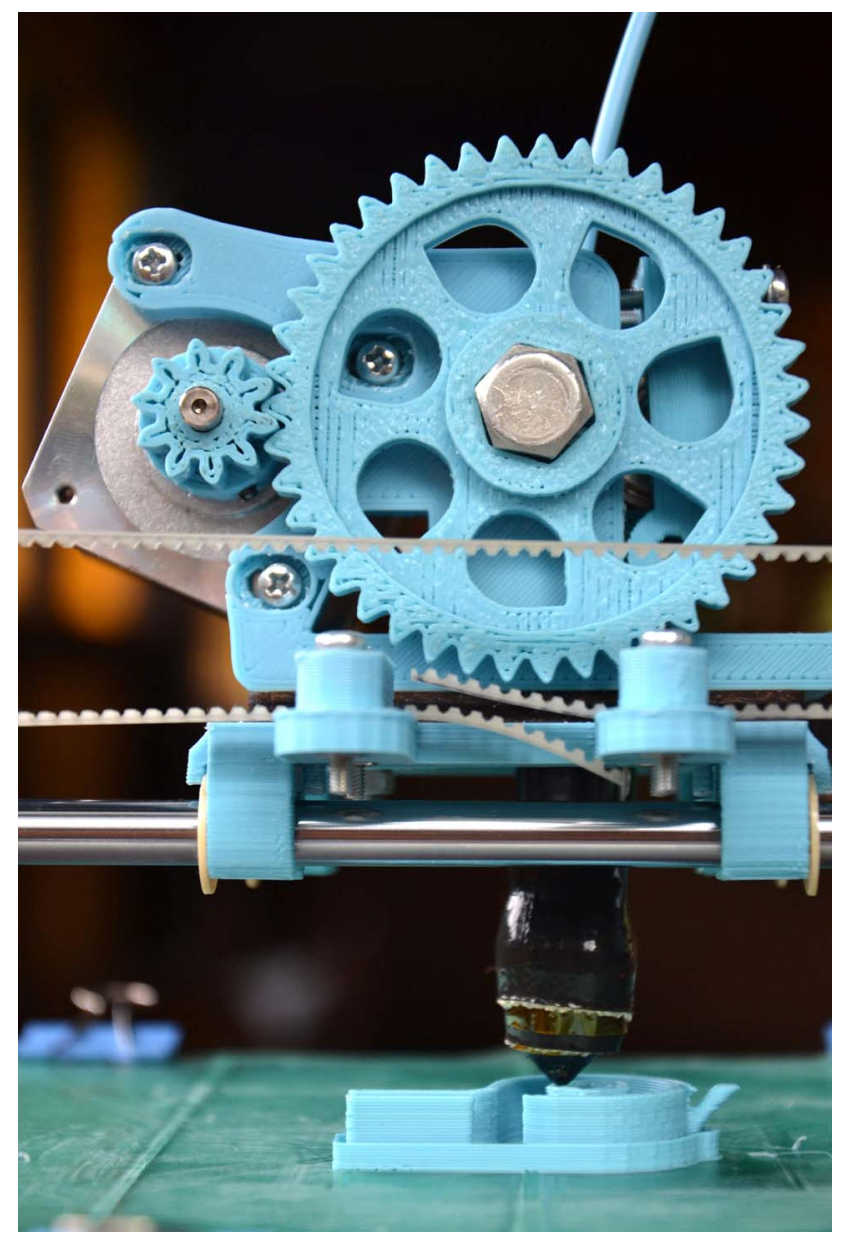

Figure $43 \mathrm{D}$ printer printed by a 3D printer.

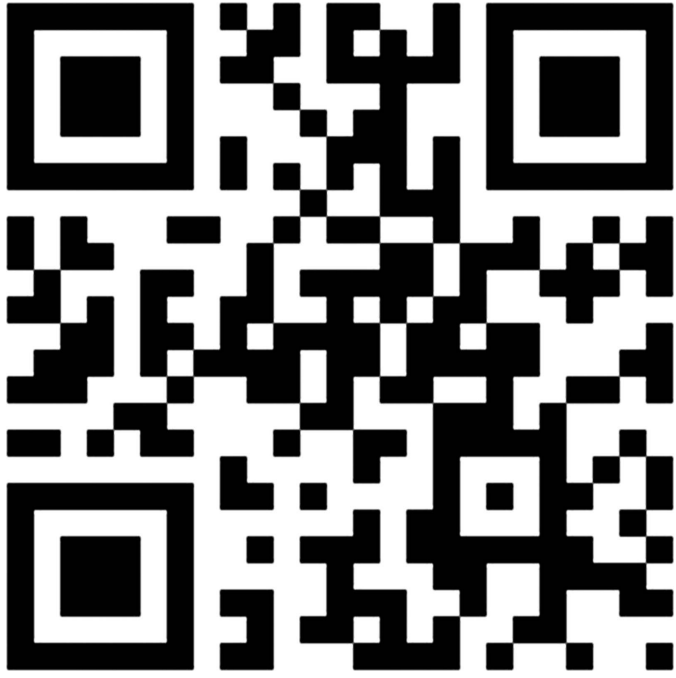

Figure 5 QR code. Scan to view video on 3D printing.

There are many potential uses for 3D printing in medicine, including ophthalmology, which could have a significant impact in changing the ways patients are treated for various conditions in the future. A number of recent reviews have been published and include 3D printing and culture of cells, blood vessels and vascular networks, ${ }^{4}$ bandages, ${ }^{5}$ bones, ${ }^{6}$ ears, ${ }^{7}$ exoskeletons, ${ }^{8}$ windpipes, ${ }^{9}$ dental prosthetics including a jaw bone, ${ }^{10}$ and future corneas ${ }^{11}$ entirely new organs to treat specified diseases such as diabetes, creating prosthetics that look like the body part they are replacing or supporting, stem cells, testing of new drugs using printed tissues, and customised drugs.

In the future, it is possible that pharmaceutical companies may be replaced by databases of drug compounds which would be emailed to the pharmacy for pharmacy printing only the amounts of drugs that are required ${ }^{12} 13$ Furthermore, it may be possible that vaccines could be delivered via email to the pharmacy at point of care, then printed and administered. ${ }^{13}$ This means of drug distribution would radically change the present delivery methods and would most certainly be less costly. In a similar manner, it will be possible to print out a patient's living tissue as a strip which can then serve as a test site for administering a variety of medications to find the most efficacious one to treat for the particular illness. ${ }^{13} 14$

$3 \mathrm{D}$ printing is also being investigated as a potential source to repair or replace defective organs, such as kidneys, heart or skin. In addition, it also has the potential to create entirely new organs which would perform the same biological functions as the diseased, non-functioning organ such as a pancreas in the case of diabetes. ${ }^{15}$ This could be a significant advancement in the treatment of disease and to alleviate the shortage of organ transplants, where currently there are about 120000 people in the USA who are waiting for an organ transplant (see www.OPTN.transplant. hrsa.gov/data). Part of the paradigm in this treatment is that organ transplantation involves finding a tissue match. This issue could potentially disappear if organs could be printed and grown using cells from the patient's own body.

In summary, 3D printing may be helpful in medicine because the process could potentially be used to make any kind of organ. By using seed material from the patient's own tissue, the problems of tissue rejection caused by inflammatory responses including tissue graft versus host rejection from heterologous tissue sources could be avoided, as well as the necessity for patients to take lifelong immunosuppressants. Proof of concept 
has been done, but the organs that have been manufactured are miniature and not complex. ${ }^{16} 3 \mathrm{D}$ printing gives rise to the possibility that entirely new organs not in the shape of the parent organ may be produced. It is conceivable that a 'liver' or 'pancreas' could be produced as, for example, a tube-shaped organ.

At the present time, however, the impact of $3 \mathrm{D}$ printing in medicine is still small, but it has the potential to grow into an enormously beneficial technology. The entire 3D printing industry is currently a $\$ 700$ million industry, with only $\$ 11$ million invested in medical applications (roughly 2\%). In the next 10 years it is expected to grow to an $\$ 8.9$ billion industry, of which $\$ 1.9$ billion is projected to be for medicine. ${ }^{17}$

Acknowledgements The authors thank Michael Armbruster of incept3D in San Diego, California who provided a figure and a set of 3D printed glasses. For further information see (http://www.incept3D.com).

Contributors All authors took part in the development of the manuscript including the writing of the manuscript. MCvanL also provided samples of 3D printed sculptures for use in figure 2.

\section{Competing interests None.}

Provenance and peer review Not commissioned; externally peer reviewed.

\section{REFERENCES}

1 Febvre L, Martin H-J. The Coming of the Book: The Impact of Printing 1450-1800. Verso World History Series, 1976.

2 Hull C. Apparatus for Production of Three-Dimensional Object by Stereolithography. U. S. Patent 4,575,330, 1986.

3 NASA to launch 3D printer into space to help supply astronauts. Theregister.co.UK, October 1, 2013
4 Miller JS, Stevens KR, Yang MT, et al. Rapid casting of patterned vascular networks for perfusable engineered three-dimensional tissues. Nat Mater 2012:11:768-74.

5 Jeong JE, Chan V, Cha C, et al. "Living" Microvascular Stamp for Patterning of Functional Neovessels; Orchestrated Control of Matrix Property and Geometry. Adv Mater 2012;24:58-63.

6 Leukers B, Gulkan H, Irsen SH, et al. Hydroxyapatite scaffold for bone tissue engineering made by 3D printing. J Mater Sci Makter Med 2005;16:1121-4.

7 Mannoor MS, Jiang A, James T, et al. 3D Printed bionic ears. Nano Lett 2013;13:2634-9.

8 Haumont T, Rahman T, Sample W, et al. Wilmington Robotic Exoskeleton: A Novel Device to Maintain Arm Improvement in Muscular Disease. J Pediatr Orthop B 2011;31:44-9.

9 Zopf DA, Hollister SJ, Nelson ME, et al. Bioresorable Airway Splint Created with a Three-Dimensional Printer. N Engl J Med 2013;368:2043-45.

10 Fielding GA, Bandyopadhyay A, Bose $S$. Effects of silica and zinc oxide doping on mechanical and biological properties of $3 \mathrm{D}$ printed tricalcium phosphate tissue engineering scaffolds. Dent Mater 2012;28:113-22.

11 Robotics Research Group. Bldg 106 Albany. Auckland, New Zealand. http://www. mechatronics.massey.ac.nz

12 Symes MD, Kitson PJ, Yan J, et al. Integrated 3D-printed reaction ware for chemical synthesis and analysis. Nat Chem 2012;4:349-54.

13 Faulkner-Jones A, Greenough S, King JA, et al. Development of a valve-based cell printer for the formation of human embryonic stem cell spheroid aggregates. Biofabrication 2013;5:015013.

14 Csete M. Translational prospects for human induced pluripotent stem cells. Regen Med 2010;5:509-19.

15 Mukherjee $S$. The five most promising uses of 3D printing in medicine. http://www. thinkprogress.org, 2013.

16 Atala A, Kasper FK, Mikos AG. Engineering Complex Tissues. Sci Trans/ Med 2012;14:162rv12.

17 Wohlers Associates. What is 3D printing? Wohler's Report 2013. http://www. wohlersassociaes.com/3D-printing.html 